\title{
Nível de convergência dos princípios contábeis brasileiros e norte-americanos às normas do IASB: uma contribuição para a adoção das IFRS por empresas brasileiras*
}

\section{The convergence level of the brazilian and american accounting principles with IASB standards: a contribution to brazilian companies' adoption of IFRS}

Valdiney Alves Oliveira

Professor Efetivo da Faculdade de Ciências Contábeis da Universidade Federal de Uberlândia.

E-mail: valdiney@facic.ufu.br

\section{Sirlei Lemes}

Professora Doutora em Contabilidade e Controladoria - Professora Associada da Universidade Federal de Uberlândia.

E-mail: sirlemes@uol.com.br

Recebido em 21.09.2010 - Aceito em 30.11.2010 - $3^{a}$. versão aceita em 29.04.2011

\section{RESUMO}

A presente pesquisa teve como objetivo avaliar em que nível as informações contábeis divulgadas nos mercados: brasileiro e norte-americano atendem aos requisitos da adoção inicial das IFRS - International Financial Reporting Standards. A adoção das IFRS por companhias abertas brasileiras nas suas demonstrações contábeis consolidadas foi exigida pela Comissão de Valores Mobiliários (CVM) na Instrução CVM $457 / 07$. Por meio de uma pesquisa descritiva quanto aos seus objetivos e utilizando-se dos procedimentos técnicos de pesquisa documental e de análise de conteúdo clássica, foram analisadas as demonstrações contábeis elaboradas para o ano de 2008 de acordo com os US GAAPs e os BR GAAPs de 20 empresas brasileiras listadas simultaneamente na Bolsa de Valores de Nova York (NYSE) e na Bolsa de Valores de São Paulo (BOVESPA) e calculou-se o índice de disclosure proposto na pesquisa de Lopes e Rodrigues (2007). A pesquisa apontou para índices de disclosure calculados para o Form $20 \mathrm{~F}$ maiores do que aqueles calculados para as Demonstrações Financeiras Padrão (DFP), confirmando um nível de convergência maior entre US GAAP e IFRS e sugerindo que, em função da adoção das IFRS as demonstrações contábeis em BR GAAP tendem a se modificar substancialmente aumentando o nível de divulgação. Além disso, os resultados confirmam para a amostra, o exposto na literatura selecionada de que o setor de atuação e o tamanho da empresa influem diretamente no disclosure das informações. Em relação aos auditores, o fato de as demonstrações serem auditadas pelas empresas globais de auditoria conhecidas como Big Four não foi determinante na extensão do disclosure.

Palavras-chave: Adoção de Normas Contábeis Internacionais. Convergência Contábil. IFRS. Disclosure Contábil.

\section{ABSTRACT}

This study aimed to assess the extent to which accounting information disclosed in the Brazilian and

\footnotetext{
*Artigo apresentado no $10^{\circ}$. Congresso USP de Controladoria e Contabilidade, São Paulo, SP, 2010.
} 
North American markets meet the requirements for the initial adoption of IFRS - International Financial Reporting Standards. The Brazilian Securities Commission (CVM) required the adoption of IFRS by Brazilian companies in CVM Instruction 457/07. Through a descriptive study about their goals and using the technical procedures of information retrieval and classical content analysis, we analyzed the financial statements prepared for the year 2008 in accordance with U.S. GAAP and B.R. GAAP of 20 Brazilian companies listed both on the Stock Exchange of New York (NYSE) and the Bolsa de Valores de Sao Paulo (BOVESPA), and calculated the rate of disclosure proposed in the study by Lopes and Rodrigues (2007). The research pointed out that the rates of disclosure calculated for Form 20F were higher than those calculated for the Standard Financial Statements (DFP), confirming a higher degree of convergence between U.S. GAAP and IFRS and suggesting that, due to IFRS adoption, financial statements in BR GAAP tend to change substantially, increasing the level of disclosure. Furthermore, for the sample, the results confirm what was presented in the selected literature about the direct influence of market sector and firm size on information disclosure. For auditors, the fact that global audit companies known as the Big Four audited the statement did not determine the extent of disclosure.

Keywords: Adoption of International Financial Reporting Standards. Accounting Convergence. IFRS. Disclosure.

\section{INTRODUÇÃO}

A integração dos mercados de capitais possibilita que investidores sejam capazes de empregar recursos financeiros em qualquer lugar do mundo sem que necessitem residir no país em que seu capital esteja alocado.

Assim, a oportunidade, conceituada por Martins (2006) como a possibilidade de escolha entre duas ou mais alternativas viáveis de investimentos, se concretiza, permitindo que os investidores obtenham ganhos com redução de riscos e as empresas obtenham o capital necessário para financiamento de seus projetos, reduzindo a escassez de recursos e consequentemente o seu custo.

Para que seja possível a escolha entre as alternativas de investimentos, a contabilidade, por meio de seus relatórios contábeis, subsidia os investidores com informações úteis e relevantes para a escolha de tais alternativas.

Ademais, Iudícibus (1995, p.18) assevera que "a função fundamental da contabilidade têm permanecido inalterada desde os seus primórdios, sendo sua finalidade prover os usuários de demonstrações financeiras com informações que os ajudarão a tomar decisões".
Dessa forma, a comparabilidade das informações produzidas pela contabilidade torna-se relevante no contexto dessas escolhas, considerando que ela é a base para a tomada de decisão por parte dos investidores sobre em qual empreendimento empregar seu capital.

Como forma de estímulo ao fluxo de capitais entre os países membros da União Europeia, o Parlamento Europeu estabeleceu, por meio do Regulamento 1.606/2002, a adoção das Normas Contábeis Internacionais conhecidas como Internacional Financial Reporting Standards (IFRS) emitidas pelo International Accounting Standards Board (IASB), a partir do exercício findo em 31 de dezembro de 2005 para as demonstrações contábeis consolidadas (EUROPEAN UNION PARLIAMENT, 2002).

Antunes, Antunes e Penteado (2007) afirmam que a adoção de normas internacionais de contabilidade pelas empresas mundiais está associada a benefícios econômicos concretos na forma de atração de maior volume de investimentos, uma vez que o processo de globalização trouxe para o primeiro plano a demanda por informações contábeis confiáveis e comparáveis 
para suportar a variedade de transações e operações desse mercado.

Corroborando com a tendência mundial de convergência para as IFRS e tencionando a acessibilidade ao mercado global de capitais por parte das empresas brasileiras, a Comissão de Valores Mobiliários (CVM) aprovou em 13 de julho de 2007, a Instrução no 457 que torna obrigatória a adoção dessas normas para as companhias abertas brasileiras nas suas demonstrações contábeis consolidadas a partir do exercício social findo em 31 de dezembro de 2010, sendo seus pressupostos: i) a convergência (tornar as informações comparáveis); ii) a transparência e a confiabilidade e iii) e a acessibilidade ao mercado global de capitais (CVM, 2008).

Assim, a tendência de convergência contábil mundial insere-se definitivamente no contexto brasileiro com a obrigatoriedade de adoção das IFRS para as companhias abertas listadas na CVM, tornando importante avaliar em quais aspectos as empresas brasileiras deverão centrar para o cumprimento dos requisitos da adoção das IFRS em 2010.

Dessa forma, a questão problema que orientou a realização deste trabalho foi: Qual o nível de aderência das demonstrações contábeis de empresas brasileiras não financeiras listadas simultaneamente na BOVESPA e na NYSE elaboradas em BR GAAP e US GAAP em relação às exigências da IFRS 1 ?
Este estudo tenciona auxiliar na compreensão de aspectos relevantes na adoção das Normas Internacionais de Contabilidade (IFRS) pelas empresas brasileiras.

Assim, ele tem como objetivo principal identificar em que nível as informações contábeis divulgadas nos mercados: brasileiro e norte-americano, por empresas listadas na BOVESPA e na NYSE simultaneamente, atendem aos requisitos da adoção inicial das IFRS. Como objetivos específicos pretendem-se:

- Delimitar e coletar uma amostra de empresas brasileiras não financeiras, listadas na BOVESPA e na NYSE simultaneamente, que estarão obrigadas a elaborar suas demonstrações em IFRS, a partir do exercício findo em 31 de dezembro de 2010, e que ainda não adotaram voluntariamente tais normas até 31 de dezembro de 2008;

- Calcular o nível de convergência das demonstrações contábeis em BR GAAP e US GAAP das empresas da amostra.

O presente trabalho encontra-se estruturado em quatro seções, além da seção inicial. A seção dois trata da fundamentação teórica; na seção três, apresenta-se a metodologia e descrevemse as empresas da amostra; na quarta seção, realiza-se a análise dos resultados obtidos; e, na última seção, encontram-se as considerações finais como encerramento do trabalho.

\section{FUNDAMENTAÇÃO TEÓRICA}

Nessa seção, serão abordados aspectos do processo de convergência de normas contábeis bem como o papel do IASB nesse processo de convergência, o impacto da adoção pela primeira vez em outros países e as necessidades de informação dos usuários supridas por meio da evidenciação ou disclosure contábil.

\subsection{O processo de convergência de normas contábeis, o papel do IASB e do CPC}

A contabilidade é considerada a linguagem global no mundo dos negócios e seus objetivos, conforme Iudícibus, Martins e Carvalho (2005), decorrem, sobretudo, das necessidades de seus usuários. Ela tem por finalidade atender os usuários com informa- 
ções relevantes, úteis e em tempo hábil, as quais serão utilizadas para controle, planejamento, avaliação e tomada de decisão.

Essas informações devem ser fiéis aos fatos, bem como transparentes, levando à confiabilidade e mostrando neutralidade por parte de quem as gerou. "A Contabilidade é, objetivamente, um sistema de informação e avaliação destinado a prover seus usuários com demonstrações e análises de natureza econômica, financeira, física e de produtividade, com relação à entidade objeto de contabilização" (IUDÍCIBUS; MARTINS; GELBCKE, 2000, p. 42).

Nesse contexto, a adoção de uma linguagem comum internacionalmente é capaz de produzir benefícios concretos quando da tomada de decisão por parte desses usuários.

De acordo com Lemes (2000), problemas contábeis oriundos das diferenças existentes nas práticas contábeis adotadas entre países não são recentes, porém, a partir da elevação do aumento do volume de investimentos internacionais e do fluxo de capital e de negócios, da desregulamentação de mercados, da eliminação de controles do capital nacional e da melhoria das comunicações, sobretudo a partir da década de 60, tornaram-nos estes ainda mais intensos.

Dessa forma, a possibilidade de comparação entre os relatórios contábeis emitidos nos diversos países do mundo beneficia os usuários da informação contábil (CHAIRAS e RADIANTO, 2001), principalmente aqueles originários do mercado financeiro qualificados por Lopes e Martins (2007) como intermediários financeiros, cuja função está ligada à adequada alocação dos recursos dos poupadores.

Como exemplo de diferenças entre GAAPs $^{1}$, na Tabela 1 são elencados os resultados em BR GAAP e em US GAAP de cinco grandes companhias brasileiras de diferentes setores econômicos para o ano de 2008, consideradas um portfólio de ações para um determinado investidor.

Tabela 1 Diferenças nos resultados de 2008 em BR GAAP e US GAAP

\begin{tabular}{l|c|c|c|c}
\multirow{2}{*}{\multicolumn{1}{c}{ Empresas }} & \multicolumn{3}{c}{ Em milhões de dólares } \\
\cline { 2 - 5 } & $\begin{array}{c}\text { BR } \\
\text { GAAP }\end{array}$ & $\begin{array}{c}\text { US } \\
\text { GAAP }\end{array}$ & $\begin{array}{c}\text { Diferença } \\
\text { em } \%\end{array}$ \\
\hline CEMIG & 807 & 750 & $(57)$ & $-7,1 \%$ \\
\hline Cia Vale do Rio Doce & 9.105 & 13.218 & 4.113 & $45,2 \%$ \\
\hline Petrobrás & 14.115 & 18.879 & 4.764 & $33,8 \%$ \\
\hline Tele Norte Leste Participações & 494 & 430 & $(64)$ & $-13,0 \%$ \\
\hline TELESP S/A & 1.035 & 1.070 & 35 & $3,4 \%$ \\
\hline TOTAL & 25.556 & 34.347 & 8.791 & $34,4 \%$ \\
\hline
\end{tabular}

Fonte: Baseada nos relatórios DFP e 20F das empresas da amostra.

Os resultados elencados na Tabela 1 , por si só, demonstram como as normas contábeis podem diferir. Desse modo, considerando que essas companhias remunerem o capital nelas investido de acordo com os US GAAP, por exemplo, um capitalista que investiu nesse portfólio de ações receberia, nesse período, uma remuneração superior àquela percebida de acordo com os BR GAAP.

Assim, o objetivo do processo de convergência contábil é integrar as práticas contábeis entre os países para atender a necessidade de informação contábil, especialmente, por parte dos mercados financeiros. Esse processo 
de convergência tenciona adequar diferenças de GAAPs existentes, de modo a permitir a comparabilidade e tornar o capital ainda mais dinâmico entre as economias globais envolvidas.

Contudo, essa convergência é possível quando os fatores determinantes elencados por Carvalho (2008), por exemplo: a tributação, a cultura, o ambiente econômico, o treinamento dos profissionais de contabilidade, o ambiente político e social, o mercado de capitais e o controle, encontram-se harmonicamente orientados na busca da linguagem global.

O órgão que tem por objetivo alcançar essa convergência global é o IASB. Ele é o órgão sucessor do antigo IASC (International Accounting Standards Commitee) que foi criado em 1973 a partir da associação entre organismos profissionais de contabilidade dos seguintes países: Austrália, Canadá, França, Alemanha, Japão, México, Holanda, Reino Unido, Irlanda e Estados Unidos por ocasião do Congresso Internacional de Contadores em Melbourne sendo um órgão independente do setor privado com sede em Londres na Grã Bretanha (NIYAMA, 2008).

A importância desse órgão reside na integração e emissão de normas contábeis em nível internacional uma vez que ele conta com a participação de todos os órgãos componentes do IFAC (International Federation of Accountants).

O IFAC é uma organização global fundada em 1977 voltada para o exercício da profissão contábil cuja missão é servir o interesse público. Esse órgão representa mais de 2,5 milhões de contadores atuando como auditores nas atividades de indústria, comércio, governo e academia (IFAC, 2009).

Diante do exposto, percebe-se que o IASB foi criado dentro de um processo de convergência de práticas contábeis, pois reuniu órgãos de vários países e apesar de ele não ter poderes para impor suas normas contábeis localmente, sua influência bem como dos demais órgãos envolvidos no processo é capaz de assegurar a sua aceitação nos diversos países.

No Brasil, mais especificamente, o processo de convergência tem na criação do CPC (Comitê de Pronunciamentos Contábeis), por meio da Resolução 1.055/05, o seu principal marco, sendo que o modelo adotado é o mesmo estabelecido pelo IASB por meio das IFRS.

O CPC é um comitê formado por entidades ligadas ao mercado de capitais para possibilitar uma uniformização de regras contábeis de modo a permitir o alcance dos objetivos da contabilidade estabelecidos em Iudícibus (1995, p.19) e, tal como o IASB não tem poderes para impor suas normas localmente, mas destaca-se como o condutor da elaboração e divulgação das normas brasileiras de contabilidade.

O processo de convergência, no Brasil, culminou na assinatura do Memorando de Entendimentos entre o CFC, o CPC e o IASB, em 28 de janeiro de 2010, e, de acordo com o CPC (2010), constitui-se em um importante marco na inserção do Brasil no diálogo internacional sobre a elaboração e a adoção das IFRS.

Conforme agenda do CPC, todos os pronunciamentos necessários à convergência contábil brasileira para as IFRS se encontram emitidos e as audiências públicas para a revisão de alguns deles encontram-se encerradas (CPC, 2011).

\subsection{A adoção das IFRS pela primeira vez em outros países}

A adoção das IFRS na União Europeia tem como marco a decisão do Parlamento Europeu em 2002 por meio da Resolução 1.606/02, embora as normas do IASB fossem aceitas desde 1995 pela IOSCO (International Organization of Securities Commissions) e a partir dessa decisão iniciaram-se as mudanças nos diversos países para que eles se adequassem aos princípios embutidos naquelas normas. 
De um modo geral, Larson e Street (2004) resumem os problemas e as mudanças que deveriam acontecer em 17 países europeus para a adoção das IFRS conforme a exigência do Parlamento Europeu.

No Quadro 1, apresentam-se os principais obstáculos encontrados e os países que os apresentaram conforme a pesquisa desses autores.

Larson e Street (2004) identificaram que, para a adoção das Normas Contábeis Internacionais em vários daqueles países, foi necessária uma alteração na estrutura conceitual da contabilidade e consideraram que deveriam ocorrer mudanças no ambiente regulatório para facilitar o processo de adoção das IFRS.

Dessa forma, para que haja de fato uma convergência para as normas do IASB, deve-se levar em conta a necessidade de mudanças, pelo menos em parte, da estrutura contábil conceitual do país no qual as IFRS serão adotadas como normas contábeis oficiais.

Quadro 1 Principais obstáculos encontrados na adoção das IFRS na Europa

\begin{tabular}{|l|l|}
\hline Obstáculos encontrados & Países \\
\hline Natureza tributária da contabilidade & $\begin{array}{l}\text { Bulgária, Eslováquia, Hungria, Lituânia, } \\
\text { Polônia, República Tcheca e Suíça }\end{array}$ \\
\hline Mercado de capitais subdesenvolvido & $\begin{array}{l}\text { Bulgária, Eslováquia, Islândia, Letônia, } \\
\text { Polônia e República Tcheca }\end{array}$ \\
\hline Natureza complexa das IFRS & Bulgária, Eslováquia, Letônia e Lituânia \\
\hline Guia insuficiente ou ausência de guia para implementação & $\begin{array}{l}\text { Letônia, Lituânia, Polônia e República } \\
\text { Tcheca }\end{array}$ \\
\hline Custo do projeto de convergência e falta de recursos financeiros & Eslováquia e Letônia \\
\hline Regras conflitantes com as normas locais & Letônia e Lituânia \\
\hline Falta de interesse na mudança para IFRS & Islândia e Polônia \\
\hline Os relatórios eram para autoridades fiscais & Romênia \\
\hline Satisfação com os princípios locais & Noruega \\
\hline Limitado conhecimento sobre as IFRS & Lituânia \\
\hline Disclosure local simplificado & Estônia \\
\hline $\begin{array}{l}\text { Normas voltadas para bancos e mercado de capitais, porém muito diferen- } \\
\text { tes das IFRS }\end{array}$ & Turquia \\
\hline Não apresentou conclusões & Liechtenstein e Malta \\
\hline Não foram encontrados obstáculos relevantes & Chipre e Eslovênia \\
\hline
\end{tabular}

Fonte: Baseado em Larson e Street (2004).

No tópico a seguir, discute-se a evidenciação contábil e suas implicações no alcance dos objetivos da contabilidade.

\subsection{Evidenciação Contábil (Disclosure)}

O termo evidenciação é definido por Iudícibus e Marion (2001) como:

[...] O processo pelo qual a empresa apresenta todas as informações que permitam a avaliação de sua situação patrimonial e das mutações de seu patrimônio e, além disso, que possibilitem a realização de inferências no futuro. As informações não passíveis de apresentação explícita nas demonstrações propriamente ditas devem, ao lado das que representam detalhamento de valores sintetizados nessas mesmas demonstrações, estar contidas em notas explicativas e em 
quadros suplementares (IUDÍCIBUS; MARION, 2001, p. 88).

Dessa forma, evidenciação contábil ou disclosure é o ato de divulgar informações úteis mostrando os fatos que as fundamentam, possibilitando a avaliação e a tomada de decisão.

Healy e Palepu (2001, p. 406) afirmam que "o disclosure corporativo é crítico para o funcionamento de um mercado de capitais eficiente" (tradução do autor). Nesse aspecto, eles argumentam que a demanda por informações financeiras decorrem da assimetria da informação e dos conflitos de agência entre administradores e investidores externos.

Em um mercado cujo principal diferencial competitivo (quer seja na captação de recursos ou na aplicação em investimentos mais rentáveis) reside na informação, as regras aplicadas pelo moderno mercado de capitais na divulgação da informação mostram-se capazes de reduzir a assimetria da informação entre os administradores de recursos e os investidores.

Dessa forma, a evidenciação funciona como um item auxiliar na solução do problema de assimetria de informação entre os investidores e os administradores.

Carvalho, Lemes e Costa (2006) destacam as quatro características qualitativas da informação estabelecidas no Framework Conceitual do IASB que a torna útil para os usuários e asseveram que a informação deve ser:

[...]

a) Prontamente compreensível aos usuários;

b) Relevante aos usuários para a tomada de decisão;

c) Confiável, sendo essa característica expressa por demonstrações: i) que representem fielmente as transações e outros eventos; ii) nas quais prevaleçam a essência e a realidade econômica sobre a forma legal; iii) que sejam neutras, isto é, livres de viés; iv) que resultem do exercício da prudência, considerando incertezas inevi- táveis e v) que sejam completas dentro dos limites de materialidade e custo.

d) Comparável com a informação fornecida pela entidade em seus relatórios contábeis ao longo do tempo e em relação a outras empresas (CARVALHO; LEMES; COSTA, 2006, p. 22).

Assim, para que a evidenciação alcance os objetivos estabelecidos no Conceptual Framework elencados pelos autores supracitados nela devem estar contidos os aspectos referentes ao reconhecimento e a mensuração de itens ativos, passivos e de resultados conforme estabelecidos pelas Normas Internacionais de Contabilidade.

\subsection{A adoção das IFRS pela primeira vez: a IFRS 1}

A adoção das Normas Internacionais de Contabilidade implica a elaboração de demonstrações financeiras seguindo todos os aspectos estabelecidos nos pronunciamentos vigentes durante o período de transição. $\mathrm{O}$ período de transição compreende a data de início do período mais antigo para o qual a empresa apresenta informação comparativa completa de acordo com as IFRS.

Assim, as empresas brasileiras obrigadas a divulgar as demonstrações em IFRS a partir do exercício findo em 31 de dezembro de 2010, devem apresentar informação comparativa para, pelo menos, um período e sua data de transição é o exercício iniciado em 01 de janeiro de 2009, cujo balanço foi encerrado em 31 de dezembro de 2009.

O princípio-chave da adoção inicial é a aplicação retroativa de todas as demais normas vigentes na data de transição, excetuando-se certos aspectos os quais se encontram estabelecidos na IFRS $1^{2}$. Essas exceções constituem-se em isenções e proibições na aplicação retrospectiva de modo a facilitar a adoção inicial das Normas Internacionais de Contabilidade. 


\section{METODOLOGIA}

Para a consecução dos objetivos estabelecidos na presente pesquisa foi realizado um estudo descritivo que, segundo Gil (2002), tem como objetivo primordial a descrição de características de determinada população ou fenômeno e o estabelecimento de relações entre variáveis.

Quanto aos procedimentos técnicos, Andrade $(2004$, p. 20) afirma que "eles são a maneira pela qual se obtêm os dados necessários para a elaboração da pesquisa”. Para a realização deste estudo utilizou-se da pesquisa documental relativa ao tema estudado.

Em relação aos procedimentos técnicos para a elaboração e a análise dos índices de disclosure tencionando o alcance dos objetivos da pesquisa, utilizou-se da técnica de análise de conteúdo, que, de acordo com Bauer (2002, p. 190), “é apenas um método de análise de texto, desenvolvido dentro das ciências sociais empíricas, sendo uma técnica híbrida que pode mediar a improdutiva discussão sobre virtudes e métodos".

A seleção das empresas da amostra deu-se mediante a aplicação dos seguintes critérios de escolha:
- selecionaram-se companhias abertas com ações negociadas na BOVESPA e na NYSE simultaneamente, não pertencentes ao setor financeiro, obrigadas a adotar as IFRS de acordo com a Instrução CVM 457/07 e obrigadas a arquivar o Form 20F na Securities and Exchange Commission (SEC) em 2008;

- excluíram-se as empresas que já haviam adotado voluntariamente as IFRS até 31 de dezembro de 2008, as empresas cujas demonstrações se encontravam consolidadas nas demonstrações de outras empresas da amostra e aquelas cujos relatórios não estavam disponíveis ao público em 30 de setembro de 2009, sendo que essa data foi estabelecida como data de finalização da coleta de dados.

A seleção das entidades de acordo com os critérios estabelecidos resultou em uma amostra de 20 empresas relacionadas na Tabela 2 e foram coletados 40 relatórios (20 DFP e 20 Form 20F) para o ano de 2008.

Os relatórios foram obtidos no sítio eletrônico da CVM e da NYSE, respectivamente (CVM, 2009; NYSE, 2009).

Tabela 2 Relação de empresas da amostra

\begin{tabular}{l|l|l|r|l}
\hline \multicolumn{1}{|c|}{ Nome Empresas } & \multicolumn{1}{|c|}{ Setor de Atuação } & \multicolumn{1}{c}{$\begin{array}{c}\text { PL em } \\
\text { milhões de } \\
\text { R\$ (BR GAAP) }\end{array}$} & \multicolumn{1}{c}{ Tamanho } \\
\hline 1 & Aracruz Celulose S. A. & Papel e Celulose & 962,5 & Pequena \\
\hline 2 & Brasil Telecom Participações S. A. & Telecomunicações & $5.763,6$ & Pequena \\
\hline 3 & Braskem S. A. & Química & $3.679,9$ & Pequena \\
\hline 4 & Companhia Brasileira de Distribuição & Comércio & $5.407,7$ & Pequena \\
\hline 5 & Companhia Energética de Minas Gerais - CEMIG & Energia Elétrica & $9.364,4$ & Grande \\
\hline 6 & Companhia Paranaense de Energia (COPEL) & Energia Elétrica & $8.053,1$ & Grande \\
\hline 7 & Companhia Siderúrgica Nacional & Siderurgia e Metalurgia & $6.662,6$ & Grande \\
\hline 8 & Companhia Vale do Rio Doce (Vale) & Mineração & $96.275,0$ & Grande \\
\hline 9 & CPFL Energia S. A. & Energia Elétrica & $5.018,6$ & Pequena \\
\hline 10 & Embraer - Empresa Brasileira de Aeronáutica & Veículos e Peças & $5.970,5$ & Grande \\
\hline 11 & Perdigão S. A. & Alimentos e Bebidas & $4.110,6$ & Pequena \\
\hline 12 & Petrobras - Petróleo Brasileiro S. A. & Petróleo e Gás & $138.365,3$ & Grande \\
\hline
\end{tabular}


continuação

\begin{tabular}{l|l|l|r|l}
\hline \multicolumn{1}{|c|}{$\mathbf{N}^{\mathbf{1}}$} & \multicolumn{1}{|c|}{ Nome Empresas } & \multicolumn{1}{|c}{ Setor de Atuação } & \multicolumn{1}{c}{$\begin{array}{c}\text { PL em } \\
\text { milhões de } \\
\text { R\$ (BR GAAP) }\end{array}$} & \multicolumn{1}{c}{ Tamanho } \\
\hline 13 & Sadia S. A. & Alimentos e Bebidas & 410,9 & Pequena \\
\hline 14 & Tele Norte Leste Participações S. A. & Telecomunicações & $9.591,0$ & Grande \\
\hline 15 & Telecomunicações de São Paulo S. A. - Telesp & Telecomunicações & $10.045,7$ & Grande \\
\hline 16 & Telemig Celular Participações S. A. & Telecomunicações & $1.793,6$ & Pequena \\
\hline 17 & Tim Participações S. A. & Telecomunicações & $7.790,5$ & Grande \\
\hline 18 & Ultrapar Participações S. A. & Química & $4.650,1$ & Pequena \\
\hline 19 & Vivo Participações S. A. & Telecomunicações & $8.267,5$ & Grande \\
\hline 20 & Votorantim Celulose e Papel S. A. & Papel e Celulose & $4.131,9$ & Pequena \\
\hline & Total & & $336.314,9$ & \\
\hline
\end{tabular}

Para o cálculo e a análise dos índices de aderência dos relatórios elaborou-se um roteiro para a análise de conteúdo das demonstrações a partir dos requisitos de cada IFRS que as empresas devem cumprir quando da adoção pela primeira vez das IFRS em vigor na data da pesquisa. As IFRS foram obtidas no sítio eletrônico do IASB (IASB, 2009).

Foram excluídas da análise as seguintes normas: IAS 8 (Políticas Contábeis, Estimativas e Erros); IAS 26 (Contabilidade e Emissão de Relatório para Planos de Benefício de Aposentadoria); IAS 29 (Demonstrações Financeiras em Economias Hiper-inflacionárias); IAS 34 (Relatórios Financeiros Intermediários) e IFRS 4 (Contratos de Seguros).

A razão para a exclusão da IAS 8 reside no fato de que conforme o parágrafo $7 \mathrm{da}$ IFRS 1 uma entidade deverá aplicar as mesmas políticas contábeis em suas primeiras demonstrações em IFRS, não havendo, portanto, mudanças nas políticas adotadas, para as IAS 26 e IFRS 4, não foram encontradas na amostra entidades cujo ramo de atividade fosse regulamentado em tais normas. Em relação à IAS 29, nenhuma empresa analisada encontrava-se operando em países de economia hiperinflacionária. A exclusão da IAS 34 deveu-se ao fato de que não foram utilizados relatórios intermediários. Além disso, foram excluídas, também, aquelas normas estudadas por Malaquias (2008). No trabalho do autor supracitado, foram estudadas as normas relativas aos instrumentos financeiros (IAS 32, IAS 39 e IFRS 7). As IFRS que fizeram parte do roteiro encontram-se elencadas no Quadro 2.

O roteiro - elaborado por Oliveira (2010) - foi composto de 294 itens verificáveis, subdivididos conforme estabelecidos pelas IFRS em Mensuração (19 itens), Reconhecimento (52 itens) e Divulgação (223 itens) e foi aplicado a cada demonstração individualmente, considerando duas situações:

i) quando o item da norma em análise se aplicava na demonstração contábil analisada (DFP ou 20F), esse recebia 1 ponto; quando não se aplicava, recebia 0 . O objetivo dessa análise foi totalizar as questões aplicáveis em cada demonstração, sendo seu resultado incluído como denominador para a Equação (1);

ii) verificada a quantidade de questões aplicadas a cada empresa em cada conjunto de relatório, analisava-se, para aqueles itens que eram aplicáveis, se era ou não atendido naquela demonstração, recebendo novamente a pontuação 1 para os itens cumpridos e 0 para os itens não cumpridos, sendo esse resultado incluído como numerador da Equação (1). 
Quadro 2 Relação de normas analisadas no estudo

\begin{tabular}{|c|c|c|c|c|c|}
\hline$N^{\circ}$ IASB & $\mathrm{N}^{\circ} \mathrm{CPC}$ & Assunto & $N^{\circ}$ IASB & $\mathrm{N}^{\circ} \mathrm{CPC}$ & Assunto \\
\hline IAS 1 & CPC 26 & $\begin{array}{l}\text { Apresentação das Demonstrações } \\
\text { Financeiras }\end{array}$ & IAS 31 & CPC 19 & $\begin{array}{l}\text { Tratamento Contábil de Partici- } \\
\text { pação em Empreendimentos em } \\
\text { Conjunto }\end{array}$ \\
\hline IAS 2 & CPC 16 & Estoques & IAS 32 & $\begin{array}{c}\text { CPC } \\
08,14 \\
\text { e } 39\end{array}$ & $\begin{array}{l}\text { Instrumentos Financeiros: Divulga- } \\
\text { ção e Apresentação }\end{array}$ \\
\hline IAS 7 & СРC 03 & Demonstração dos Fluxos de Caixa & IAS 33 & CPC 41 & Lucro por Ação \\
\hline IAS 8 & CPC 23 & $\begin{array}{l}\text { Políticas Contábeis, Estimativas e } \\
\text { Erros }\end{array}$ & IAS 34 & CPC 21 & $\begin{array}{l}\text { Relatórios Financeiros Intermedi- } \\
\text { ários }\end{array}$ \\
\hline IAS 10 & СРC 24 & $\begin{array}{l}\text { Eventos Subsequentes à Data do } \\
\text { Balanço }\end{array}$ & IAS 36 & СРC 01 & $\begin{array}{l}\text { Reduação ao Valor Recuperável } \\
\text { de Ativos }\end{array}$ \\
\hline IAS 11 & CPC 17 & Contratos de Construção & IAS 37 & CPC 25 & $\begin{array}{l}\text { Provisões, Passivos e Ativos Con- } \\
\text { tingentes }\end{array}$ \\
\hline IAS 12 & CPC 32 & Imposto de Renda & IAS 38 & СРC 04 & Ativos Intangíveis \\
\hline IAS 16 & CPC 27 & Ativo Imobilizado & IAS 39 & $\begin{array}{c}\text { CPC } \\
08,14 \\
\text { e } 38\end{array}$ & $\begin{array}{l}\text { Instrumentos Financeiros: Reco- } \\
\text { nhecimento e Mensuração }\end{array}$ \\
\hline IAS 17 & CPC 06 & Arrendamentos & IAS 40 & CPC 28 & Propriedades para Investimentos \\
\hline IAS 18 & CPC 30 & Receita & IAS 41 & CPC 29 & Agricultura \\
\hline IAS 19 & СРC 33 & Benefícios aos Empregados & IFRS 1 & $\begin{array}{c}\text { СРC } 37 \\
\text { e } 43\end{array}$ & $\begin{array}{l}\text { Primeira Aplicação das Normas } \\
\text { Internacionais de Contabilidade }\end{array}$ \\
\hline IAS 20 & СРC 07 & $\begin{array}{l}\text { Contabilidade de Concessões } \\
\text { Governamentais e Divulgação de } \\
\text { Assistência Governamental }\end{array}$ & IFRS 2 & CPC 10 & Pagamentos Baseados em Ações \\
\hline IAS 21 & СРC 02 & $\begin{array}{l}\text { Efeitos das Alterações nas Taxas de } \\
\text { Câmbio }\end{array}$ & IFRS 3 & CPC 15 & Combinações de Negócios \\
\hline IAS 23 & CPC 20 & Custos de Empréstimos & IFRS 4 & CPC 11 & Contratos de Seguros \\
\hline IAS 24 & СРC 05 & Divulgações de Partes Relacionadas & IFRS 5 & CPC 31 & $\begin{array}{l}\text { Ativos Não Correntes Mantidos } \\
\text { para Venda e Operações Descon- } \\
\text { tinuadas }\end{array}$ \\
\hline IAS 26 & N/D & $\begin{array}{l}\text { Contabilidade e Emissão de Rela- } \\
\text { tórios para Planos de Benefício de } \\
\text { Aposentadoria }\end{array}$ & IFRS 6 & $\mathrm{~N} / \mathrm{D}$ & $\begin{array}{l}\text { Exploração e Avaliação de Recur- } \\
\text { sos Minerais }\end{array}$ \\
\hline IAS 27 & $\begin{array}{l}\text { СРC } 35 \\
\text { e } 36\end{array}$ & $\begin{array}{l}\text { Demonstrações Financeiras Con- } \\
\text { solidadas e Contabilidade para } \\
\text { Investimentos em Subsidiárias }\end{array}$ & IFRS 7 & CPC 40 & $\begin{array}{l}\text { Instrumentos Financeiros: Divul- } \\
\text { gações }\end{array}$ \\
\hline IAS 28 & CPC 18 & $\begin{array}{l}\text { Contabilidade para Investimentos } \\
\text { em Associadas }\end{array}$ & IFRS 8 & CPC 22 & Segmentos Operacionais \\
\hline IAS 29 & $\mathrm{~N} / \mathrm{D}$ & $\begin{array}{l}\text { Demonstrações Financeiras em } \\
\text { Economias Hiperinflacionárias }\end{array}$ & & & \\
\hline
\end{tabular}

Todos os itens foram analisados considerando o mesmo peso. Foram considerados como atendidos (1 ponto) apenas aqueles que, na demonstração analisada, apresentaram evidências de cumprimento total, não considerando, portanto, atendimento parcial 
da questão apresentada no roteiro.

Assim, os índices foram calculados por meio da Equação (1):

IC $=\frac{S}{T} \times 100$

em que:

IC: índice de convergência do relatório analisado;

S: número de itens atendidos na demonstração analisada;
T: número de questões aplicáveis na demonstração analisada.

Em razão da quantidade de itens avaliados, exemplificam-se, no Quadro 3, algumas questões constantes do roteiro elaborado por Oliveira (2010) e aplicado às demonstrações das empresas analisadas, sendo que, para cada norma analisada, foram elaboradas questões pertinentes aos quesitos mensuração, reconhecimento e divulgação:

Quadro 3 Roteiro para análise de conteúdo das demonstrações

\begin{tabular}{|c|c|c|c|c|c|c|}
\hline \multicolumn{7}{|c|}{ IAS 12 - Imposto de Renda } \\
\hline \multirow{2}{*}{ Item } & \multirow{2}{*}{ Bloco Mensuração } & \multirow{2}{*}{ Score } & \multicolumn{2}{|c|}{ Cumpre } & \multicolumn{2}{|c|}{ Pág e nota } \\
\hline & & & $20 F$ & DFP & $20 \mathrm{~F}$ & DFP \\
\hline 1 & $\begin{array}{l}\text { Utilização da alíquota fiscal vigente e promulgada ou substancialmente } \\
\text { promulgada na data do balanço. }\end{array}$ & & & & & \\
\hline \multicolumn{7}{|c|}{ IAS 12 - Imposto de Renda } \\
\hline \multirow{2}{*}{ Item } & \multirow{2}{*}{ Bloco Reconhecimento } & \multirow{2}{*}{ Score } & \multicolumn{2}{|c|}{ Cumpre } & \multicolumn{2}{|c|}{ Pág e nota } \\
\hline & & & $20 \mathrm{~F}$ & DFP & $20 \mathrm{~F}$ & DFP \\
\hline 1 & $\begin{array}{l}\text { Utilização da abordagem da diferença temporária na contabilização do } \\
\text { imposto de renda diferido. }\end{array}$ & & & & & \\
\hline 2 & $\begin{array}{l}\text { Avaliação da probalidade de geração de lucros tributáveis futros para o } \\
\text { reconhecimento e a manutenção do imposto de renda diferido. }\end{array}$ & & & & & \\
\hline \multicolumn{7}{|c|}{ IAS 12 - Imposto de Renda } \\
\hline \multirow{2}{*}{ Item } & \multirow{2}{*}{ Bloco Divulgação } & \multirow{2}{*}{ Score } & \multicolumn{2}{|c|}{ Cumpre } & \multicolumn{2}{|c|}{ Pág e nota } \\
\hline & & & $20 \mathrm{~F}$ & DFP & $20 \mathrm{~F}$ & DFP \\
\hline 1 & $\begin{array}{l}\text { Divulgação dos motivos para reconhecimento de imposto de renda } \\
\text { diferido sobre prejuízos fiscais e diferenças temporárias. }\end{array}$ & & & & & \\
\hline 2 & $\begin{array}{l}\text { Divulgação das movimentações do período para o imposto de renda } \\
\text { diferido ativo e passivo. }\end{array}$ & & & & & \\
\hline 3 & $\begin{array}{l}\text { Reconciliação da taxa efetiva utilizando-se dos valores nominais ou } \\
\text { percentuais. }\end{array}$ & & & & & \\
\hline
\end{tabular}

Fonte: Oliveira (2010, p. 115)

A aplicação desse roteiro às demonstrações deu-se por meio da análise de conteúdo, mantendo a coerência do estudo de Lopes e Rodrigues (2007). Tal coerência fez-se necessária em razão de o estudo supramencionado ter sido a referência na realização da presente pesquisa, a qual representa uma replicação no Brasil do tra- balho dessas autoras para empresas portuguesas.

Os limites da presente pesquisa estão relacionados aos seguintes aspectos:

- empresas da amostra: o trabalho focou apenas aquelas que estão listadas na NYSE, não levando em consideração o fato de que outras empresas brasileiras 
estarão obrigadas, a partir do exercício findo em 31 de dezembro de 2010, a publicar suas demonstrações contábeis de acordo com as IFRS.

- estudo das normas: foco apenas nos aspectos gerais das IFRS para atendimento a IFRS 1, não se aprofundando, especificamente, em nenhuma delas.

- procedimento metodológico: a análise de conteúdo baseou-se apenas nos documentos disponíveis para o público em geral e não houve nenhum contato com as empresas da amostra para verificar outros documentos ou para a obtenção de informações diferenciadas disponíveis para os analistas de mercado dessas empresas.

- atribuição de notas: utilização de uma pontuação binária, do tipo atende ( 1 ) ou não atende (0), sendo que em relação às análises efetuadas, é possível que alguns requisitos se encontrem próximos do atendimento aos requisitos das IFRS, contudo não foram considerados atendidos em função da escala binária.

- peso dos itens avaliados: todos os itens foram avaliados com o mesmo peso, desconsiderando a importância relativa de cada um deles para a empresa, quer seja em relação ao objeto da empresa ou em relação à relevância do item na demonstração analisada. Por exemplo, o fato de a participação dos minoritários, tanto no padrão US GAAP quanto no BR GAAP, não estar incorporada ao patrimônio líquido da entidade, não pode, por si só, constituir-se em um item relevante, já que se encontra divulgado na demonstração de posição financeira da entidade e pode ser perfeitamente analisado por parte de analistas e investidores especializados como se fora divulgado no PL. Porém, para efeito de atendimento ao disposto na IAS 24 (Divulgações das Partes Relacionadas), encontra-se em desacordo com o estabelecido por ela.

\section{ANÁLISE DOS RESULTADOS}

A aplicação do roteiro nas demonstrações analisadas resultou no cálculo individual dos índices de aderência apresentados na Tabela 3 e para avaliar a teoria de que empresas maiores tendem a obter índices maiores, conforme estabelecido no trabalho de Lopes e Rodrigues (2007) e Malaquias (2008), a amostra das empresas foi segmentada em pequenas e grandes. Para tanto, o atributo considerado na divisão entre pequenas e grandes empresas foi o Patrimônio Líquido (PL).

Assim, calculou-se a mediana do PL da amostra, e as empresas cujo PL estava abaixo desse montante foram consideradas pequenas enquanto aquelas cujo PL estava acima desse valor foram consideradas grandes. A mediana considerada ficou em torno de R\$
5,9 bilhões. O PL e a classificação dessas empresas em pequenas e grandes podem ser visualizados na Tabela 2 apresentada na seção 3 da presente pesquisa.

A divisão das empresas em médias e grandes, utilizando como referência a mediana do PL, seria alterada, caso houvesse a inclusão de uma ou mais empresas, porém, na amostra selecionada (20 empresas), a divisão contemplou exatamente metade delas consideradas como grandes e a outra metade como pequenas empresas, sem prejuízo das análises efetuadas para este estudo.

$\mathrm{Na}$ Tabela 3, apresentam-se os índices individualmente alcançados pelas empresas da amostra para os dois relatórios estudados e consolidados em pequenas e grandes empresas. 
Tabela 3 Índices de aderência individuais e consolidados por tamanho de empresa

\begin{tabular}{|c|c|c|c|}
\hline $\mathbf{N}^{\circ}$ & Nome Empresas & $20 \mathrm{~F}$ & DFP \\
\hline 1 & Aracruz Celulose S. A. & 53,90 & 52,48 \\
\hline 2 & Brasil Telecom Participações S. A. & 65,85 & 54,27 \\
\hline 3 & Braskem S. A. & 60,64 & 50,53 \\
\hline 4 & Companhia Brasileira de Distribuição & 67,10 & 56,77 \\
\hline 5 & Companhia Energética de Minas Gerais - CEMIG & 50,90 & 50,30 \\
\hline 6 & Companhia Paranaense de Energia - COPEL & 63,53 & 50,00 \\
\hline 7 & Companhia Siderúrgica Nacional & 59,87 & 47,37 \\
\hline 8 & Companhia Vale do Rio Doce (Vale) & 59,65 & 57,89 \\
\hline 9 & CPFL Energia S. A. & 61,58 & 50,28 \\
\hline 10 & Embraer - Empresa Brasileira de Aeronáutica & 52,17 & 47,83 \\
\hline 11 & Perdigão S. A. & 56,90 & 47,70 \\
\hline 12 & Petrobras - Petróleo Brasileiro S. A. & 62,31 & 55,28 \\
\hline 13 & Sadia S. A. & 56,00 & 48,57 \\
\hline 14 & Tele Norte Leste Participações S. A. & 60,67 & 54,49 \\
\hline 15 & Telecomunicações de São Paulo S. A. - Telesp & 62,43 & 49,72 \\
\hline 16 & Telemig Celular Participações S. A. & 61,07 & 51,68 \\
\hline 17 & Tim Participações S. A. & 62,02 & 51,94 \\
\hline 18 & Ultrapar Participações S. A. & 65,07 & 53,42 \\
\hline 19 & Vivo Participações S. A. & 61,94 & 47,74 \\
\hline 20 & Votorantim Celulose e Papel S. A. & 43,71 & 43,11 \\
\hline \multicolumn{2}{|c|}{ Média Geral } & 59,25 & 51,03 \\
\hline \multicolumn{2}{|c|}{ Média das dez menores empresas } & 59,11 & 50,73 \\
\hline \multicolumn{2}{|c|}{ Média das dez maiores empresas } & 62,04 & 53,61 \\
\hline \multicolumn{2}{|c|}{ Desvio padrão das dez menores empresas } & 6,96 & 3,83 \\
\hline \multicolumn{2}{|c|}{ Desvio padrão das dez maiores empresas } & 4,40 & 3,58 \\
\hline
\end{tabular}

Analisando-se a Tabela 3, é possível verificar que os índices de aderência dos relatórios elaborados segundo os US GAAP foram maiores do que aqueles elaborados segundo os BR GAAP para todas as empresas da amostra.

Uma das explicações para esse fato reside na constatação realizada por Lemes e Carvalho (2009) acerca da assinatura do acordo de convergência (Norwalk Agreement Memorandum) em 2002 entre FASB e IASB reafirmado pelo MoU (Memorandum of Understanding) em 2006. $\mathrm{O}$ acordo previa a eliminação das diferenças até 2008, porém os eventos necessários para a convergência plena entre US GAAP e IFRS ainda estão em fase de discussão e aprovação e estendem-se até o ano de 2011. Outra justificativa pode estar relacionada com o nível de exigência de divulgações dos US GAAP serem maiores do que os BR GAAP conforme abordado no estudo de Darós e Borba (2005).

No Brasil, a norma contábil local encontra-se em processo de convergência para as IFRS e, em 31 de dezembro de 2008, ainda não continha em seu arcabouço todas as exigências impostas pelo IASB para o exercício de 2008, analisadas no presente estudo. A convergência plena das normas brasileiras está prevista para o exercício findo em 31 de dezembro de 2010 no Memorando de Enten- 
dimentos entre o CFC, o CPC e o IASB assinado em 28 de janeiro de 2010 (CPC, 2010).

Verifica-se, ainda, que para a maioria das empresas da amostra, os resultados nos BR GAAP (65\% da amostra) e nos US GAAP (95\% da amostra) cumprem com mais de $50 \%$ dos requisitos das IFRS. Em estudo anterior, Malaquias (2008) apresentou, para os instrumentos financeiros, índices de disclosure maiores do que $50 \%$ para $15 \mathrm{em}$ presas $(62,5 \%$ da amostra) no Form $20 \mathrm{~F}$ e apenas para uma empresa (4,2\% da amostra) analisando-se a DFP.

Existem duas possíveis razões para que tenha havido uma elevação desses índices na DFP em relação à pesquisa do autor supracitado: a adoção da Lei 11.638/07 a partir do exercício findo em 31 de dezembro de 2008 a qual alterou a norma contábil nacional, iniciando, dessa forma, o processo de convergência contábil brasileiro às normas contábeis do IASB e o fato de o autor analisar a aplicação das normas relacionadas a instrumentos financeiros, consideradas no trabalho de Larson e Street (2004), mais complexas do que as demais IFRS por alguns países, tratado na seção 2.2.

Em relação ao Form 20F, a elevação ocorre em função dos eventos resultantes da agenda de convergência FASB/IASB, conforme já mencionado.

No entanto, apesar da elevação dos índices calculados no 20F, a diferença média entre eles e aqueles calculados na DFP foi de $8 \%$, sugerindo uma aproximação substancial entre os dois conjuntos de princípios. Para o relatório DFP, 7 empresas (35\% da amostra) apresentaram índices menores do que $50 \%$, enquanto no $20 \mathrm{~F}$ apenas uma empresa ( $5 \%$ da amostra) apresentou índice menor do que $50 \%$.

Os resultados apresentados na Tabela 3 convalidam a afirmação de Lopes e Rodrigues (2007) e comprovam os resultados encontrados por Malaquias (2008) de que empresas maiores tendem a alcan- çar índices de disclosure maiores, embora, individualmente, a empresa com o maior índice encontrado no Form 20F foi a Cia Brasileira de Distribuição $(67,1 \%)$ que fez parte do grupo das dez menores empresas, enquanto na DFP a empresa que apresentou o maior índice foi a Cia Vale do Rio Doce e fez parte do grupo das dez maiores empresas.

O desvio-padrão dos índices das maiores empresas apresentou-se menor do que o desvio-padrão das empresas menores, sugerindo uma consistência maior na divulgação daquelas constantes do grupo das maiores empresas em relação às que fazem parte do grupo das menores empresas, confirmando o exposto no parágrafo anterior.

Ressalte-se que das dez maiores empresas consideradas na amostra apenas três (Companhia Siderúrgica Nacional, Cia Vale do Rio Doce e Embraer) delas não fazem parte de setores regulamentados. Porém para duas delas, o índice de disclosure encontra-se acima da média das maiores empresas no Form 20F (ver Tabela 3), enquanto na DFP apenas uma obteve índice superior a essa média.

Stanga (1976) afirma, em seu trabalho, que a extensão do disclosure está relacionada com o setor de atuação. Assim, em setores regulamentados, o nível de disclosure tende a ser maior do que em outros setores.

No contexto desse trabalho, entende-se por setores regulamentados aqueles ligados diretamente a uma agência reguladora ou que seja concessionária de algum serviço público, conforme enumerado no trabalho de Grotti (2006). Dessa forma, os setores regulamentados considerados nesse trabalho são: energia elétrica, petróleo e gás e telecomunicações.

Na Tabela 4, encontram-se os índices por setor de atuação das empresas da amostra e a média dos índices considerando os requisitos das IFRS (mensuração, reconhecimento e divulgação). 
Tabela 4 Índices por setor de atuação e requisito das IFRS

\begin{tabular}{|c|c|c|c|c|c|}
\hline \multirow{2}{*}{$\mathbf{N}^{\circ}$} & \multirow{2}{*}{ Setor de Atuação } & \multicolumn{2}{|c|}{ Índices } & \multicolumn{2}{|c|}{ Ranking } \\
\hline & & $20 \mathrm{~F}$ & DFP & $20 \mathrm{~F}$ & DFP \\
\hline 1 & Alimentos e Bebidas & 56,45 & 48,14 & 8 & 7 \\
\hline 2 & Comércio & 67,10 & 56,77 & 1 & 2 \\
\hline 3 & Energia Elétrica & 58,75 & 50,19 & 7 & 6 \\
\hline 4 & Mineração & 59,65 & 57,89 & 6 & 1 \\
\hline 5 & Papel e Celulose & 48,38 & 47,40 & 10 & 9 \\
\hline 6 & Petróleo e Gás & 62,31 & 55,28 & 4 & 3 \\
\hline 7 & Química & 62,57 & 51,80 & 2 & 4 \\
\hline 8 & Siderurgia e Metalurgia & 59,87 & 47,37 & 5 & 10 \\
\hline 9 & Telecomunicações & 62,34 & 51,67 & 3 & 5 \\
\hline 10 & Veículos e Peças & 52,17 & 47,83 & 9 & 8 \\
\hline \multicolumn{2}{|c|}{ Média dos Setores Regulamentados } & 61,23 & 51,65 & & \\
\hline \multicolumn{2}{|c|}{ Média dos Setores não Regulamentados } & 57,28 & 50,42 & & \\
\hline \multicolumn{2}{|c|}{ Média do requisito Mensuração } & 81,20 & 79,87 & & \\
\hline \multicolumn{2}{|c|}{ Média do requisito Reconhecimento } & 78,54 & 72,01 & & \\
\hline \multicolumn{2}{|c|}{ Média do requisito Divulgação } & 52,75 & 44,26 & & \\
\hline
\end{tabular}

De acordo com os dados da Tabela 4, é possível verificar que a média dos índices dos setores regulamentados é maior do que a média dos setores não regulamentados em ambos os relatórios, corroborando a afirmação de Stanga (1976).

Porém, ao se analisar cada setor individualmente, observa-se que dois setores não regulamentados ocupam as duas primeiras posições no ranking (o setor de comércio, que ocupa a primeira posição no $20 \mathrm{~F}$ e a segunda na DFP e o setor de mineração, que ocupa a primeira posição na DFP) e apresentam índices superiores aos de algumas empresas pertencentes a setores regulamentados, contrariando a teoria apresentada por Stanga (1976). Na presente amostra, foram catalogadas uma empresa no setor de comércio e uma empresa no setor de mineração.

A explicação para que o setor de comércio alcançasse esse índice no Form 20F reside nas normas aplicáveis a esse setor de atuação, sendo que elas estão relacionadas a assuntos nos quais US GAAP e IFRS se encontram próximos e os aspectos delas nos quais houve maior pontuação se relacionam aos requisitos de Mensuração e Reconhecimento. Em tais requisitos, os métodos utilizados apresentamse bastante similares ou são permitidos pelas IFRS como tratamento alternativo.

As normas mais cumpridas pelo setor de mineração que possibilitaram que esse setor alcançasse o primeiro lugar no ranking da DFP foram a IAS 10 (Eventos Subsequentes), a IAS 21 (Efeitos das Alterações nas Taxas de Câmbio), a IAS 24 (Divulgação de Partes Relacionadas), a IAS 27 (Demonstrações Financeiras Consolidadas e Contabilidade para Investimentos em Subsidiarias), a IAS 28 (Contabilidade para Investimentos em Associadas), a IAS 31 (Tratamento Contábil de Participação em Empreendimentos em Conjunto) e a IFRS 8 (Informações por segmento).

A pesquisa é incipiente para afirmar que não existe uma relação entre setores regulamentados e disclosure, porém, para as empresas da amostra, alguns setores não regulamentados apresentaram índices maiores do que os de setores regulamentados.

Os requisitos das IFRS que demandarão mais esforços de cumprimento por parte das 
empresas brasileiras, estão, em sua maior parte, relacionados aos aspectos de divulgação, sendo que, nessa vertente, ocorreu a menor pontuação das demonstrações. A vertente mensuração foi a que obteve os maiores índices de aderência, alcançando cerca de $80 \%$ dos quesitos das IFRS.

No presente estudo, foi analisado se os índices de disclosure calculados para as demonstrações contábeis auditadas pelas empresas de auditoria conhecidas como Big
Four $^{3}$ se apresentam maiores do que aqueles calculados pelas demais empresas de auditoria, conforme afirmado no trabalho de Chalmers e Godfrey (2004). De acordo com esses autores, a experiência global do auditor pode exercer uma influência significativa na extensão do disclosure. No total da amostra, 3 empresas (1,5\%) não são auditadas pelas Big Four. Os índices calculados por empresa de auditoria estão apresentados na Tabela 5 .

Tabela 5 Índices por empresa de auditoria

\begin{tabular}{c|l|c|c|c}
\hline $\mathbf{N}^{\mathbf{0}}$ & \multicolumn{1}{|c|}{ Empresa de Auditoria } & Qtde. Emp. & $\mathbf{2 0 F}$ & DFP \\
\hline 1 & Deloitte Touche Tohmatsu & 4 & 60,99 & 53,72 \\
\hline 2 & Ernst \& Young Auditores Independentes & 4 & 63,13 & 51,41 \\
\hline 3 & KPMG Auditores Independentes & 8 & 59,14 & 50,51 \\
\hline 4 & Price Waterhouse Coopers Auditores Independentes & 1 & 52,17 & 47,83 \\
\hline 5 & BDO Trevisan Auditores Independentes & 1 & 60,67 & 54,49 \\
\hline 6 & Directa Auditores & 1 & 62,02 & 51,94 \\
\hline 7 & Terco Grant Thornton Auditores Independentes & 1 & 43,71 & 43,11 \\
\hline
\end{tabular}

Analisando-se os índices calculados para essas empresas, percebe-se que, para dois terços das empresas de auditoria (2) que não fazem parte das Big Four, eles se apresentam acima dos índices alcançados por $50 \%$ das empresas de auditoria (2) componentes das
Big Four tanto na DFP quanto no 20F.

Conclui-se, portanto, a partir da Tabela 5, que, embora a auditoria tenha participação ativa no disclosure de informações, o fato de fazer parte do grupo das Big Four não foi determinante na sua extensão para as empresas da amostra.

\section{CONSIDERAÇÕES FINAIS}

A partir da decisão da CVM de determinar a adoção das normas contábeis estabelecidas pelo IASB para o exercício fiscal findo em 31 de dezembro de 2010, o Brasil insere-se, definitivamente, no contexto de uma contabilidade globalizada voltada, também, para os interesses dos usuários originados do mercado financeiro.

Diante desse quadro, a questão que direcionou este estudo relacionou-se ao nível de aderência das demonstrações contábeis de empresas brasileiras não financeiras listadas simultaneamente na BOVESPA e na NYSE elaboradas em BR GAAP e US GAAP em relação às exigências das IFRS.

A proposta do trabalho foi avaliar em que nível as informações contábeis, divulgadas nos mercados: brasileiro e norte-americano, por empresas listadas na BOVESPA e na NYSE simultaneamente, atendem aos requisitos da adoção inicial das IFRS. 
Para tanto, por meio da análise de conteúdo, foram analisados os relatórios Form 20F e DFP de empresas brasileiras não financeiras, listadas simultaneamente na BOVESPA e na NYSE no ano de 2008, construindo-se os índices de disclosure conforme metodologia proposta por Lopes e Rodrigues (2007) para empresas portuguesas e replicada por Malaquias (2008) para empresas brasileiras em relação às exigências das normas relativas a instrumentos financeiros (IAS 32, IAS 39 e IFRS 7).

Os relatórios analisados não têm a obrigação de atender aos requisitos das IFRS, porém, em função da convergência para as IFRS das normas contábeis dos países nos quais eles são exigidos, a análise desses relatórios se constitui em uma avaliação qualitativa do seu conteúdo, contribuindo para a adoção das IFRS em 2010, conforme Instrução CVM 457/07.

A pesquisa apontou para índices de disclosure calculados para o Form 20F maiores do que aqueles calculados para a DFP, confirmando um nível de convergência maior entre US GAAP e IFRS e sugerindo que, em função da adoção das IFRS, as demonstrações contábeis em BR GAAP tendem a se modificar substancialmente aumentando o nível de divulgação.

Além disso, os resultados corroboram, para a amostra, o exposto na literatura selecionada de que o tamanho das empresas influi diretamente no disclosure das informações, porém, em função de a adoção inicial das IFRS ocorrer considerando um dado período de tempo não comportando uma série temporal, não foi possível avaliar a significância estatística desse resultado.

Em relação ao setor, os resultados parecem confirmar que ele é determinante na extensão do disclosure embora duas empresas pertencentes a setores não regulamentados tenham obtidos índices superiores ao de empresas de setores regulamentados, ressalvada a impossibilidade da realização do teste de significância.

Em relação aos auditores, verificou-se que os índices encontrados na maioria das demonstrações auditadas por empresas que não pertenciam ao grupo das empresas globais de auditoria (Big Four) não são menores do que os índices das demonstrações auditadas pelas Big Four. Assim, o fato de a demonstração ser auditada por uma empresa global de auditoria não foi determinante na extensão do disclosure, embora os auditores tenham participação ativa nele, ressalvando-se que a adoção inicial das IFRS exigida pela Instrução CVM no 457/07 ocorrem em relação a uma dada demonstração não comportando uma série temporal e, portanto, não sendo possível calcular sua significância estatística.

Por meio da atuação dos órgãos $\mathrm{CPC} e$ CVM, verificou-se que as normas contábeis brasileiras estão em processo de convergência para as IFRS, porém, considerando o resultado encontrado nas demonstrações analisadas, é possível concluir que ainda existe algum trabalho a ser realizado para a convergência plena das normas brasileiras, uma vez que o maior índice encontrado na DFP correspondeu ao atendimento de $57,8 \%$ dos requisitos das IFRS.

Os limites da presente pesquisa estão relacionados aos seguintes aspectos: i) empresas da amostra (o trabalho focou naquelas listadas simultaneamente na BOVESPA e na NYSE); ii) foco nos aspectos gerais das IFRS para atendimento às exigências da IFRS 1; iii) procedimento metodológico (a análise de conteúdo baseou-se nos documentos disponíveis ao público em geral) e iv) a avaliação de todos os itens considerando o mesmo peso, sem contudo, avaliar a importância relativa de cada um deles no cumprimento das IFRS.

Este trabalho contribui com os estudos sobre a adoção das Normas Contábeis Internacionais no contexto das empresas brasileiras e tenciona provocar uma reflexão sobre esse assunto fundamentando discussões sobre a relevância do tema no atual contexto.

Como sugestão para trabalhos futuros, recomenda-se que sejam analisados os impactos gerados internamente em uma empresa em função da complexidade da adoção das IFRS, considerando as possibilidades de escolha para cada IFRS em vigor. 


\section{Referências}

ANDRADE, M. M. de. Como preparar trabalhos para cursos de pós-graduação: noções práticas. 6. ed. São Paulo: Atlas, 2004.

ANTUNES, J.; ANTUNES, G. M. B.; PENTEADO, I. M. A convergência contábil brasileira e a adoção das normas internacionais de contabilidade: o IFRS-1. In: X SEMEAD. Anais..., São Paulo, ago. 2007.

BAUER, M.W. Análise de Conteúdo Clássica: uma revisão. In: BAUER, M. W.; GASKELL, G. Pesquisa qualitativa com texto imagem e som: um manual prático. (Tradução de Pedrinho A. Guareschi). Petrópolis: Vozes, 2002. Cap. 8. p. 189- 217.

CARVALHO, L. N. G.; LEMES, S.; COSTA, F. M. Contabilidade Internacional: Aplicação das IFRS 2005. São Paulo: Atlas, 2006.

CARVALHO E. L. Treinamento de Contabilidade Internacional - IFRS. São Paulo: FIPECAFI, 2008. 100 p. Apostila.

CHAIRAS, I. Y., RADIANTO, W. R. D. Accounting Harmonization in ASEAN: the process, benefits and obstacles. International Accounting and Finance, Master Thesis no. 2001:05, Göteborg University. Disponível em: <http:/gupea.ub.gu.se/dspace/bitstream/2077/2499/1/ Chairas_2001_5_inlaga.pdf>. Acesso em: 08 dez. 2009. CHALMERS, K., GODFREY, J. Reputation Costs: The impetus for voluntary derivative financial instrument reporting. Accounting, Organization and Society, v.29, n. 2, p. 95-125, 2004.

CPC - COMITÊ DE PRONUNCIAMENTOS

CONTÁBEIS. Memorando de Entendimentos. Publicado em 28 de Janeiro de 2010. Disponível em: <http://www. cpc.org.br/mostraNoticia.php?id_noticia $=72>$. Acesso em: 30 Jan. 2010.

. Pronunciamentos, Orientações e Interpretações

Técnicas. Disponível em: <http://www.cpc.org.br/agenda. php $>$. Acesso em: 14 mar. 2011.

CVM - Comissão de Valores Mobiliários. Instrução Normativa $n^{\circ} 457$, de 13 de julho de 2007. Dispõe sobre a elaboração e divulgação das demonstrações financeiras consolidadas, com base no padrão contábil internacional emitido pelo International Accounting Standards Board - IASB. Disponível em: <http://www.cvm.gov.br>.

Acesso em: 14 dez. 2008.

. Disponível em: $\langle h t t p: / / w w w . c v m . g o v . b r\rangle$. Acesso em: 30 set. 2009.

DARÓS, L. L.; BORBA, J. A. Evidenciação

de Instrumentos Financeiros Derivativos nas

Demonstrações Contábeis: uma análise das empresas

brasileiras. Revista Contabilidade e Finanças. São Paulo, no. 39, p. 68 - 80, set./dez. 2005.

EUROPEAN UNION PARLIAMENT. Uniform rules for international accounting standards from 2005 onwards. European Parliament Daily Notebook, European Union, 12 Mar. 2002. Disponível em: <http://www. europarl.europa.eu/sides/getDoc.do?pubRef=-//EP// TEXT+PRESS+DN-20020312-1+0+DOC+XML+V0// EN\#SECTION5>. Acesso em: 27 fev. 2010.

GIL, A. C. Como elaborar projetos de pesquisa. 4. ed. São Paulo: Atlas, 2002.
GROTTI, D. A. M. As agências reguladoras. Revista Eletrônica de Direito Administrativo Econômico. n. 6, mai/jun/jul. 2006. Disponível em: <http://www. direitodoestado.com.br/redae/edicao/06/>. Acesso em: 08 dez. 2009.

HEALY, P. M.; PALEPU, K. G. Information asymmetry, corporate disclosure, and the capital markets: A review of the empirical disclosure literature. Journal of Accounting and Economics, v.31, p. 405-440, 2001.

IASB - International Accounting Standards Board. IFRS / Standard IFRSs: 2009. Disponível em: < http://www.iasb. org/IFRSs/IFRs.htm>. Acesso em: 13 ago. 2009.

IFAC - International Federation of Accountants. About IFAC/Facts about IFAC. Disponível em: <http://web.ifac. org/download/Facts_About_IFAC.pdf $>$. Acesso em: 10 dez. 2009.

IUDÍCIBUS, S. Teoria da Contabilidade. 4. ed. São Paulo: Atlas, 1995.

; MARION, J. C. Dicionário de Termos de

Contabilidade. São Paulo: Atlas, 2001.

; MARTINS, E.; CARVALHO, L. N. Contabilidade: aspectos relevantes da epopéia de sua evolução. Revista Contabilidade e Finanças. São Paulo, nº 38, p. 7 - 19, maio/ago. 2005.

; GELBCKE, E. R. Manual de contabilidade

das sociedades por ações: aplicável às demais sociedades. 5. ed. São Paulo: Atlas, 2000.

LARSON, R. K.; STREET, D. L. Convergence with IFRS in an expanding Europe: progress and obstacles identified by large accounting firms' survey. Journal of Accounting, Auditing and Taxation, v.13, p.89-119, 2004. LEMES, S. Harmonização das normas contábeis brasileiras com as do IASC: Um estudo comparativo aplicado. 2000. 295 f. Tese (Doutorado em Ciências Contábeis)- Faculdade de Economia, Administração e Contabilidade, Universidade de São Paulo, São Paulo, 2000.

; CARVALHO, L.N.G. Comparabilidade entre o resultado em BR GAAP e US GAAP: Evidências das companhias brasileiras listadas nas bolsas norte americanas. Revista Contabilidade e Finanças. São Paulo, v. $20, n^{\circ} .50$, p. 25 - 45, Maio/Agosto 2009.

LOPES, A. B.; MARTINS, E. Teoria da Contabilidade: uma nova abordagem. São Paulo: Atlas, 2007.

LOPES, P. T.; RODRIGUES, L. L. Accounting for financial instruments: An analysis of the determinants of disclosure in the Portuguese stock exchange. The International Journal of Accounting, v. 42, p. 25-56. 2007. MALAQUIAS, R. F. Disclosure de instrumentos financeiros segundo as Normas Internacionais de Contabilidade: evidências empíricas de empresas brasileiras. 2008. $163 \mathrm{f}$. Dissertação (Mestrado em Administração)-Faculdade de Gestão e Negócios, Universidade Federal de Uberlândia, Uberlândia-MG, 2008.

MARTINS, E. (organizador). Avaliação de Empresas: da mensuração contábil à econômica. São Paulo: Atlas, 2006. NIYAMA, J. K. Contabilidade Internacional. São Paulo: Atlas, 2008.

NYSE - New York Stock Exchange. Listings Directory / European / United Kingdom. Disponível em: <http:// 
www.nyse.com/>. Acesso em: 30 set. 2009.

OLIVEIRA, V. A. Adoção Inicial das Normas Contábeis Internacionais por empresas brasileiras. 2010. $156 \mathrm{f}$.

Dissertação (Mestrado em Administração)-Faculdade de
Gestão e Negócios, Universidade Federal de Uberlândia, Uberlândia-MG, 2010.

STANGA, K.G. Disclosure in published annual reports. Financial Management, v.5, p. 42-52. 1976. 